
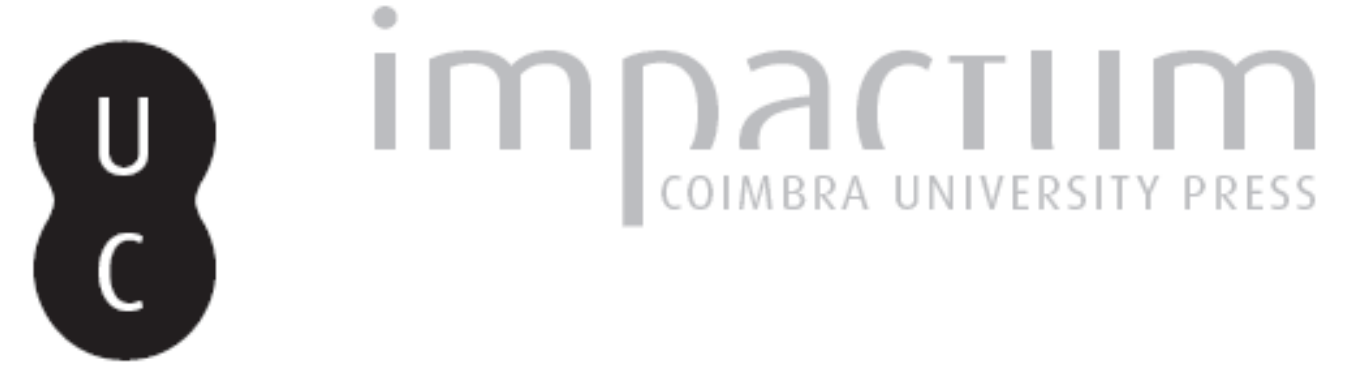

Fíbulas do museu etnográfico e arqueológico Dr. Joaquim Manso: (Nazaré)

Autor(es): $\quad$ Ponte, Sálete da

Publicado por: Imprensa da Universidade de Coimbra

URL persistente:

URI:http://hdl.handle.net/10316.2/45676

DOI:

DOI:https://dx.doi.org/10.14195/1647-8657_23_6

Accessed : $\quad$ 26-Apr-2023 10:54:50

A navegação consulta e descarregamento dos títulos inseridos nas Bibliotecas Digitais UC Digitalis, UC Pombalina e UC Impactum, pressupõem a aceitação plena e sem reservas dos Termos e Condições de Uso destas Bibliotecas Digitais, disponíveis em https://digitalis.uc.pt/pt-pt/termos.

Conforme exposto nos referidos Termos e Condições de Uso, o descarregamento de títulos de acesso restrito requer uma licença válida de autorização devendo o utilizador aceder ao(s) documento(s) a partir de um endereço de IP da instituição detentora da supramencionada licença.

Ao utilizador é apenas permitido o descarregamento para uso pessoal, pelo que o emprego do(s) título(s) descarregado(s) para outro fim, designadamente comercial, carece de autorização do respetivo autor ou editor da obra.

Na medida em que todas as obras da UC Digitalis se encontram protegidas pelo Código do Direito de Autor e Direitos Conexos e demais legislação aplicável, toda a cópia, parcial ou total, deste documento, nos casos em que é legalmente admitida, deverá conter ou fazer-se acompanhar por este aviso.

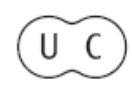


FACULDADE DE LETRAS

INSTITUTO DE ARQUEOLOGIA

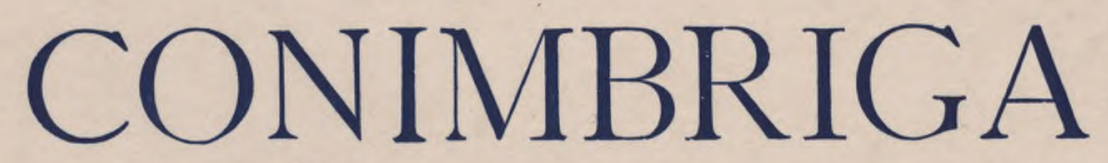

VOLUMEXXIII

UNIVERSIDADE DE COIMBRA

1984 
Sálete da Ponte

Conservadora do Museu Monográfico de Conimbriga

FÍBULAS DO MUSEU ETNOGRÁFICO E ARQUEOLÓGICO

DR. JOAQUIM MANSO (NAZARÉ)

«Conimbriga», XXIII (1984), p. 87-95

Resumo: Das seis fíbulas aqui publicadas, duas são de proveniência desconhecida; outras duas, do Casal da Mota (Nazaré), pertencem ao tipo Nauheim; os n.os 1 e 2, encontrados no Castro de Pirreitas (Alcobaça), são fíbulas atribuíveis aos séculos vm-vii a.C. e testemunham relações comerciais da região com o Mediterrâneo Central.

Summary: Six brooches from the Museum Joaquim Manso (Nazaré) are here published. The provenance of nos. 3 and 4 is unknown. Nos. 1 and 2, from Castro de Pirreitas (Alcobaça), suggest trade contacts of the area with Central Mediterranean in the 8-7th. century B.C. Nos. 5 and 6, from Casal da Mota (Nazaré), belong to the Nauheim type. 
(Página deixada propositadamente em branco) 


\section{FÍBULAS DO MUSEU ETNOGRÁFICO E ARQUEOLÓGICO DR. JOAQUIM MANSO (NAZARÉ)}

Agrupamos, neste estudo, 6 fíbulas de bronze, inéditas (1): duas (n.os 3 e 4) são de proveniência desconhecida; outras duas provêm do Castro de Pirreitas, concelho de Alcobaça (n.os 1-2); as restantes foram recolhidas no Casal da Mota, concelho da Nazaré (n. ${ }^{\text {os }}$ 5-6). Estas peças foram recentemente submetidas a tratamento adequado $\left({ }^{2}\right)$ no Museu Monográfico de Conimbriga, devido à acção corrosiva de carbonatos de cobre; estes cobriam, parcialmente, o motivo decorativo do descanso do $\mathrm{n} .^{\circ} 1$.

A fíbula $n .^{\circ} 1$ pertence ao grupo de «arco pouco engrossado com descanso em disco» (3). O arco e secção são, em regra, semicirculares; o arco aparece habitualmente decorado, ou por uma conta volumosa de pasta vítrea ou de âmbar, ou por incisões

P) Estas peças foram oferecidas pelo sr. Tito Livio Calixto ao Museu Etnográfico e Arqueológico dr. Joaquim Manso (Nazaré).

(2) Após limpeza mecânica sob a lupa binocular, estas peças, à excepção do n. $^{\circ} 1$, foram completamente impregnadas no vácuo em Benzotriazol e depois lacadas com verniz Incralac adicionado de Santocel. Este processo foi, parcialmente, aplicado ao n..$^{\circ}$, dado esta peça apresentar um arco revestido de uma pasta resinosa - que nos parece ser âmbar - e que, sob a acção directa do Benzotriazol, derreter-se-ia. Procedeu-se também à soldadura do fusilhão, por meio de estanho, dos n. ${ }^{\text {os }} \mathbf{1}$ e 6 .

(3) Cf. Alain duval, Christiane Eluère et Jean-Pierre Mohen, Les fibules antérieures au VIe siécle avant ere, trouvées en France, "Gallia», 32, 1974, p. 1-61 (= Duval, Fibules), p. 13. 
anelares transversais ou oblíquas (4); a mola é unilateral e, em regra, não tem mais de duas voltas; o descanso é discoidal e quase sempre decorado com motivos geométricos; por sua vez, une-se ao pé por meio de um anel duplo.

Este modelo provém directamente da fíbula italiana de «arco simples com disco em espiral», datável dos finais do séc. $\mathrm{x}$ a.C.

- inícios do ix a.C. $\left.{ }^{5}\right)$; este disco, inicialmente pequeno, transforma-se, posteriormente, numa placa maior que, por meio de um simples ou duplo anel, se une ao pé (6). Esta última modalidade ocorre com abundância em todo o território italiano, nomeadamente em Cumas e Vetulonia nos finais do séc. ix a.C. — inícios do viu a.C. ( ${ }^{7}$ ); a sua presença manifesta-se ainda na costa meridional francesa nos finais do séc. viu a.C., mormente em Gallarques (Gard), Bavay (Nord) e Saturarques (Hérault $\left(^{8}\right)$, sendo bastante rara na Península Ibérica. Isto faz supor que este fabrico foi largamente prejudicado pela concorrência de um outro modelo contemporâneo - a fíbula de «arco mulbicurvilíneo com mola» $\left({ }^{9}\right)$

- que oferecia outra estabilidade e flexibilidade do fusilhão, graças à nova configuração da mola unilateral. $O$ modelo de Pirreitas (Alcobaça) é, até ao momento, o único exemplar que conhecemos no país; a decoração exuberante do disco é muito semelhante à dos exemplare $^{\wedge}$ italianos $\left({ }^{10}\right)$. O seu fabrico é feito a partir de um fio forjado, onde o arco, a mola unilateral, o fusilhão e o disco são

(4) Cf. Duval, Fibules, p. 11-15, fig. 6, 3 e fig. 7, 1-3. A conta em forma de «Sanguessuga» do nosso $n .^{\circ} 1$ é de resina (âmbar).

(5) Cf. oscar montelius, La Civilisation primitive en Italie, Estocolmo,

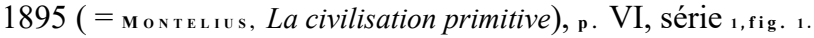

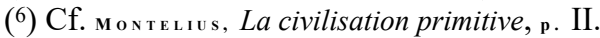

(7) Cf. montelus, La civilisation primitive, p. I; cf. duval, Fibules, p. 13, fig. $17, \mathrm{n} .5 \mathrm{~s} 1$ a 3 ; cf. alain duval e olivier buchenschutz, Les civilisations de Vdge du fer dans le Bassin Parisién et la France du Nord, «La Préhistoire Française. Les civilisations néolithiques et protohistorique de la France», vol. II, Paris, 1976, p. 789-801 (p. 791, fig. 1).

(8) Cf. Duval, Fibules, p. 13 e 43.

(9) Cf. Montelius, La civilisation primitive, p. VI, cf. Duval, Fibules, p. $30-35$.

(10) Cf. Duval, Fibules, fig. 7, n. ${ }^{\circ}$; cf. Montelius, La civilisation primitive, Est. I, 9 (Itália, localidade desconhecida); Est. II, 13 (Itália meridional, localidade desconhecida). 
feitos por estiragem e martelagem; a decoração do disco é aberta por meio $\mathrm{d}_{\boldsymbol{i}}$ buril ou ciuzel $\left({ }^{\mathrm{n}}\right)$.

Este modelo não deve ser anterior aos fináis do séc. vm a.C.-inícios do vil a.C.. A sua presença no Castro de Pirreitas, bem como a de outros objectos metálicos - punhais, braceletes e machados de bronze — no concelho de Alcobaça, testemunham a existência de relações comerciais com os vários povos do Mediterrâneo Central na Idade do Bronze e na Idade do Ferro ( $\left.{ }^{12}\right)$.

$\mathrm{O}$ n. ${ }^{\circ} 2$ pertence à vasta categoria de fíbulas de «arco multicurvilíneo» (13) ou de «arco serpenteante e mola unilateral» (14). $\mathrm{O}$ arco é de feição côncava e de secção rectangular ou circular;

(u) Cf. Jean Bourhis, Jacques Briard e Jean-Pierre Mohen, Le depot de bronze de Villethierry (Yonne), IXe suplemento de «Gallia Préhistoire», Paris, 1976, p. 163-169, fig. 143 e p. 199-200.

(12) Cf. Afonso do Paço, Grutas de Alcobaça. Aditamento, «Zephyrus», XVII, Salamanca, 1966, p. 89-99 (figs. 3-5); cf. Afonso do Paço, M. Vieira Natividade e as raizes de Alcobaça, "Arqueologia e História», vol. IX, Lisboa, 1962, p. 75-93 (p. 89, figs. 5, 6); cf. M. Vieira Natividade, Grutas de Alcobaça. Relatório dos trabalho de exploração nas diversas estações neolíticas de Alcobaça, «Portugália», vol. I, fase. 3, Lisboa, 1899-1903, p. 433-464, Est. XXII-XXIII, XXVI, XXVIII; cf. Maria amélia horta Pereira,

0 machado do Castelo da Ota e uma lâmina de punhal de S. João de Abrantes ou as culturas do cobre e do bronze na Bada do Tejo, «Actas das

1 Jornadas Arqueológicas», vol. II, Lisboa, 1970, p. 241-270 (p. 255, fig. 11, p. 269); cf. M. Almagro Gorbea, los Tesoros de Sagrajas y Buzocana y los torques de oro macizo del Occidente Peninsular, «Actas do III Congresso Nacional de Arqueologia», vol. I, Porto, 1974, p. 259-282 (p. 274 e 276); cf. Julian Pedro Garrido Roiz, Precisiones en torno a la colonización fenicia en el area atlantica de la Peninsula Ibérica y las excavaciones arqueológicas de Huelva, «XIII Congreso Nacional de Arqueologia», Saragoça, 1975, p. 773-780 (p. 780). Este autor observa que as relações comerciais da área atlántica da Península Ibérica com o Mediterráneo Oriental, mormente com colonos e comerciantes fenícios, se deve à exploração intensa da prata, do ouro e do cobre naquela região; cf. J. M. ${ }^{a}$ B Lazquez, Tartessos y los origenes de la colonización fenicia en Occidente, Salamanca, 1968, p. 53-54. O autor observa que nos finais da Idade do Bronze-inícios do Ferro, os objectos metálicos, mormente as fíbulas revelam o intenso comércio marítimo entre o Mediterráneo Oriental e o Noroeste Peninsular, devido à existência de minas de ouro, prata e estanho.

(13) Cf. Duval, Fibules, p. 30-31.

(14) Cf. Montelius, La civilisation primitive, p. Ill, VI, Est. XIV.

Conimbriga, 23 (1984), 87-95 
tem ñas extremidades um simples enrolamento que origina, respectivamente, o fusilhão e o pé; aquele é de feição rectilínea ou curvilínea; no primeiro caso, o fusilhão procede de urna só espira gigante (n. $\left.{ }^{\circ} 2\right)$; no segundo, provém de uma ou de duas voltas sobrepostas (15); o pé é alto e termina num descanso discoidal, que se une àquele por um simples ou duplo anel. É neste último caso que se situa o de Pirreitas $\left(n .^{\circ} 2\right)$. Esta modalidade é de origem itálica e situa-se entre o séc. ix a.C.-vn a.C. (16); sofre, logo depois, transformações estruturais, nomeadamente no fusilhão e no descanso; aquele, de rectilíneo, tende, a partir do séc. ix a.C., a encurvar-se; o último apresenta, nos finais do séc. $x$ a.C., um pequeno disco em espiral feito do enrolamento de um fio; posteriormente, ou seja, no séc. ix a.C., adopta um disco plano, obtido por martelagem; enfim, no séc. viu a.C., apresenta um descanso curto $\left({ }^{17}\right)$. É precisamente neste período que estes modelos surgem com abundância no Languedoc; a sua presença na Península Ibérica, conforme nos atestam os exemplares de Cerro del Berrueco (Salamanca) e La Mercadera (Sória), não se situará antes dos finais do séc. viu a.C. - inícios do vn a.C. (18). Assim, atribuiremos ao nosso exemplar um terminus post quem nos inícios do séc. vn a.C. $\left({ }^{19}\right)$. $\mathrm{O}$ fabrico deste exemplar processa-se do mesmo modo que o n. ${ }^{\circ} 1$.

Os n. ${ }^{\text {s }} 3$ e 4 pertencem ao grupo de fíbulas de «arco losangonal com apêndices laterais» $\left({ }^{20}\right)$; o arco cavado e aberto na parte superior é, nalguns casos, decorado superiormente por olhais cegos dispostos

$\left({ }^{15}\right)$ Cf. montelus, La civilisation primitive, p. IV, Est. Est. XIV, 197-202; cf. Duval, Fibules, p. 31, fig. 19, 3, 5, 7.

(16) Cf. Johannes Sundwall, Die alteren italischen Fibeln, Berlim, 1943 , p. 47-48. Este autor integra-a no grupo das serpentiformes (Sundwall DII Bb); cf. Duval, Fibules, p. 31; cf. Luciano Salzani, La necropoli delVetá del Bronzo a Fontarella Mantovana, «Preistoria Alpina», Trento, 1978, 14, p. $115-162$ (p. 140, fig. 14,6).

(17) Cf. duva , Fibules, p. 31-33.

('s) Cf. Wilhelm Schule, Die Meseta-Kulturen der Iberischen Halbinsel, Madrid, 1969, p. 32, 144, fig. 40 - tipo lb - (Cerro del Berrueco), Est. 47,1 (La Mercadera).

$\left.{ }^{19}\right)$ Atribuiremos a mesma cronologia a um exemplar provável de Alcácer do Sal que apresentámos no Congresso Nacional de Arqueologia, Faro, 1980, «As fíbulas de Alcácer do Sal», n. ${ }^{\circ} 1$.

(20) Cf. duval, Fibules, p. 26-30. 
em cruz (n. $\left.{ }^{\text {os }} 3-4\right)$, ou por simples traços transversais ou longitudinais; a mola é unilateral, de uma a três voltas; o pé é longo e, ao lateralizar-se, cria um descanso de feição triangular; o pé teimina num botão circular.

Este tipo apresenta urna técnica de fabrico diferente das fíbulas n. ${ }^{\text {os }} 1$ e 2; em primeiro lugar, o metal é vasado em estado de fusão num molde bivalve apropriado ( $\left.{ }^{21}\right)$; em seguida, por estiragem e martelagem, obtêm-se, lateralmente, a mola, o fusilhão e o descanso. Esta modalidade ocorre com abundância na Itália e na Europa Central na 2. ${ }^{\text {a }}$ metade do séc. vi a.C. (22); surge, ainda com relativa frequência, em depósitos franceses que datam, ou dos fináis do séc. vil a.C. ou de inícios do séc. vi a.C. ( $\left.{ }^{23}\right)$; é, porém, bastante rara na Península Ibérica. É crível que esta modalidade, importada inicialmente da Italia, tenha sido rapidamente imitada pelos artífices locais do Languedoc (24), que, a partir do séc. vi a.C., passaram a fabricar outros modelos (25) que tiveram desde então larga expansão na Península Ibérica.

Os n.os 5 e 6 integram-se na vasta categoria de fíbulas de tipo Nauheim (26), que engloba, por sua vez varias modalidades; estas distinguem-se, essencialmente, pelo perfil do arco, do pé e do descanso $\left({ }^{27}\right)$; têm, de comum, a mola bilateral de corda interior ou

(21) Os moldes utilizados eram de argila ou de pedra.

(22) Cf. Duval, Fibules, p. 28 e 30, fig. 16, n. 9 (Habére-Lullin-Haute-Savoie), fig. 16, n. ${ }^{\circ} \mathbf{1 0}$ (Oise ou Somme), n. 11 (Besançon-Doubs), fig. 17, n. 1 (Agen-Lot-et-Garonne), n. ${ }^{\circ} \quad 2$ e 4 (Habére-Lullin-Haute-Savoie), n. ${ }^{\circ} 3$ (Lyon-Rhone) e n. 5 (Paris-Seine); cf. Montelius, La civilisation primitive, p. VI, Est. IX, n. ${ }^{\text {ss }}$ 102-103 (Itália Meridional), 105 (necrópole Arnoaldi Bolonha) e 106 (Itália).

(23) Cf. DuVA L, Fibules, p. 30.

(24) Cf. Duval, Fibules, p. 46; cf. Jean-Claude Richard, Michel Feugère e Paul Soyris, Les fibules de Murviel-les-Montpellier (Hérault), «Archéologie en Languedoc», Languedoc, 1980, 3, p. 123-134 (p. 125-126).

(25) Cf. Duval, Fibules, p. 46. Este autor aponta como novos modelos as fíbulas serpentiformes com botão terminal no pé e as de tipo «Golfo de Leão»; cf. A. Moutinho Alarcão e Sálete da Ponte, Les objects de parure et de toilette. Les instruments de chirurgie, «Fouilles de Conimbriga», vol. VII, Paris, 1979 ( = Fouilles de Conimbriga, Vil), p. 109-126 (p. 112).

(26) Cf. Fouilles de Conimbriga, VII, p. 117.

${ }^{27}$ Cf. id. ibidem., p. 117; cf. SÁlete da Ponte, Algumas das fibulas do distrito de Setúbal, «O Arqueólogo Portugués», Lisboa, série IV, 1,1983, p. 317.

Conimbriga, 23 (1984), 87-95 
exterior ao arco, que consta sempre de 4 voltas. Além disso, $\mathrm{e}^{\wedge}$ te tipo é obtido a partir de am só fio metálico: o arco, a mola e o fusilhão constituem uma só peça.

$\mathrm{O}$ n. ${ }^{\circ} 5$ corresponde ao tipo $7 \mathrm{E}$ de Camulodunum (28) que se define, essencialmente, pelo alteamento do arco junto ao ombral ou a meio daquele, quando de secção semicircular; pelo pé terminado ou num botão ou num travessão e pela feição quadrangular do descanso. Esta modalidade ocorre com frequência em diversos locais romanos $\left({ }^{29}\right)$ entre os meados do séc. i d.C. e os finais do ii d.C.; os numerosos modelos de Vaiamonte( $\left.{ }^{30}\right)$ não nos fornecem, infelizmente, quaisquer dados estratigráficos.

O n. ${ }^{\circ} 6$ é uma variante de tipo Nauheim (31) que apresenta, essencialmente, o arco de feição quadi angular e o pé longo e estreito; a mola bilateral consta de 4 voltas e é de corda interior ao arco; o descanso é de feição quadrangular.

Este modelo corresponde ao tipo 5 de Ettlinger (32), que a autora considera uma forma evoluída do tipo pseudo - La Tène II (La Tène III) datável entre 20 a.C. e 20 d.C.; os exemplares de Lugdunum Convenarum e de Arentsbourg são, porém, datados entre os finais do séc. i d.C. e os inícios do séc. $m$ d.C. ( $\left.{ }^{33}\right)$.

(28) F. C. Hawnes e Hull, Camulodunum. First report on the excavations at Colchester 1930-1939, Oxónia, 1947, p. 132.

${ }^{29}$ ) Citemos alguns dos locais romanos que nos fornecem cronologia segura: cf. Gunter UlBert. Die rõmische Donau-Kastelle Aislingen und Burghòfe, Berlim, 1959, p. 64, Est. 14, 8; Cf. Norbert Walke, Das rõmische Donau-Kastelle Straubing-Sorviodurum, Berlim, 1965, p. 147, Est. 93, 2; cf. UlRich Fischer, Grabungen im ròmischen Steinkastell von Heddernheim 1957-1959, Frankfurt, 1973, p. 98, fig. 22, n. ${ }^{\circ}$ 4; ef. Werner Kramer, Cambodunumforschungen, 1953-1, Kallmünz, 1957, p. 63 Est. 13, n. ${ }^{\text {os }} 3-5$.

(30) Cf. Farinha dos Santos, Fíbulas recolhidas no Cabeço de Vaiamonte, «Anais da Academia Portuguesa da História», 2. ${ }^{a}$ série, 22, 1973, p. 189-200 (p. 195, n. ${ }^{\text {os }} 127,130$ e 133).

(31) Cf. Fouilles de Conimbriga, VII, p. 118.

(32) Cf. E. EtTlinger, Die ròmischen Fibeln in der Schweiz (Handbuch der Schweiz zur Rómer -und Merowingerzeit), Berna, 1973, p. 42-43, 187, Est. $2, \mathrm{n}^{\circ} 14$.

(33) R. Gavelle, Notes sur les fibules gallo-romaines recueillies à Lugdunum Convenarum (Saint-Bertrand-de-Comminges), «Ogam», XIV, 1962, p. 201-236 (p. 205-206, Est. 48, fig. 7, n. ${ }^{\circ} 6$ (4393) e 7 (4202), Est. 49, n. ${ }^{2}$ (4341). 


\section{CATÁLOGO}

1. Fíbula de «arco pouco engrossado com descanso e em espiral». Inv. n. ${ }^{\circ} 186$. Bronze. O arco, de secção semicircular é decorado por uma volumosa conta de âmbar em forma de "sanguessuga»; a mola é unilateral e consta de 4 voltas; o pé é curto e une-se ao descanso por um anel duplo; o descanso discoidal é ricamente cinzelado com motivos geométricos: a orla é decorada, alternadamente, por traços contínuos, quer sejam circulares, quer oblíquos, ou em ziguezague; a meio, o disco é decorado por 2 cruzes gamadas e 2 losangos preenchidos por traços oblíquos. Proveniência: Castro de Pirreitas (concelho de Alcobaça). Compr: $96 \mathrm{~mm}$; alt. $30 \mathrm{~mm}$. (Fot. 1).

2. Fíbula de «arco multicurvilíneo» ou de «arco serpenteante e mola unilateral». Inv. n. ${ }^{\circ}$ 185. Bronze. $O$ arco curvilíneo e de secção semicircular é cinzelado por urna fiada continua de aneis transversais que se repete no pé; a mola é unilateral e consta de urna espiral gigante; o pé é alto e une-se ao descanso por um anel duplo. Proveniencia: Castro de Pirreitas (conc. de Alcobaça). Compr.: $131 \mathrm{~mm}$; alt. máx.: $50 \mathrm{~mm}$..

3. Fíbula de «arco losangonal com apêndices laterais». Inv. n. ${ }^{\circ} 189$. Bronze. O arco é decorado por cinco olhais cegos em cruz; a mola é unilateral e consta de duas voltas; o pé e descanso são longos e estreitos; aquele termina num botão circular; o último é de feição triangular. Proveniência: desconhecida. Compr. $62 \mathrm{~mm}$; alt. $26 \mathrm{~mm}$.

4. Id. Inv. n. ${ }^{\circ}$ 190. Bronze. É idéntico ao anterior mas de proporções mais pequenas. A mola é unilateral e consta de uma só volta. Prov.: desconhecida. Compr.: $45 \mathrm{~mm}$; alt.: $20 \mathrm{~mm}$,

5. Fíbula de tipo Nauheim (Camulodunum 7E). Inv. n. ${ }^{\circ}$ 187. Bronze. $\mathrm{O}$ arco é laminar e de feição triangular; a mola bilateral e de corda exterior ao arco consta de 4 voltas; o pé é curto e termina num pequeno apêndice transversal; o descanso é de feição quadrangular. Prov.: Casal da Mota (freg. de Famalicão, conc. da Nazaré). Compr.: $123 \mathrm{~mm}$; alt.: $35 \mathrm{~mm}$.

6. Fíbula variante do tipo Nauheim (Ettlinger 5). Inv. n. ${ }^{\circ}$ 188. Bronze e vidro. $\mathrm{O}$ arco laminar e de feição quadrangular é decorado longitudinalmente por cinco finas molduras; separa-se do pé por uma pequena esfera de vidro de cor azul com uma faixa a meio, de vidro branco; o pé longo e curvo termina num botão cónico; a mola é bilateral e de corda interior ao arco consta de 4 voltas; o descanso é de feição quadrangular. Prov.: Casal da Mota (conc. da Nazaré). Compr. 80 mm; alt.: 30 mm (Fot. 2).

Conimbriga, 23 (1984), 87-95 


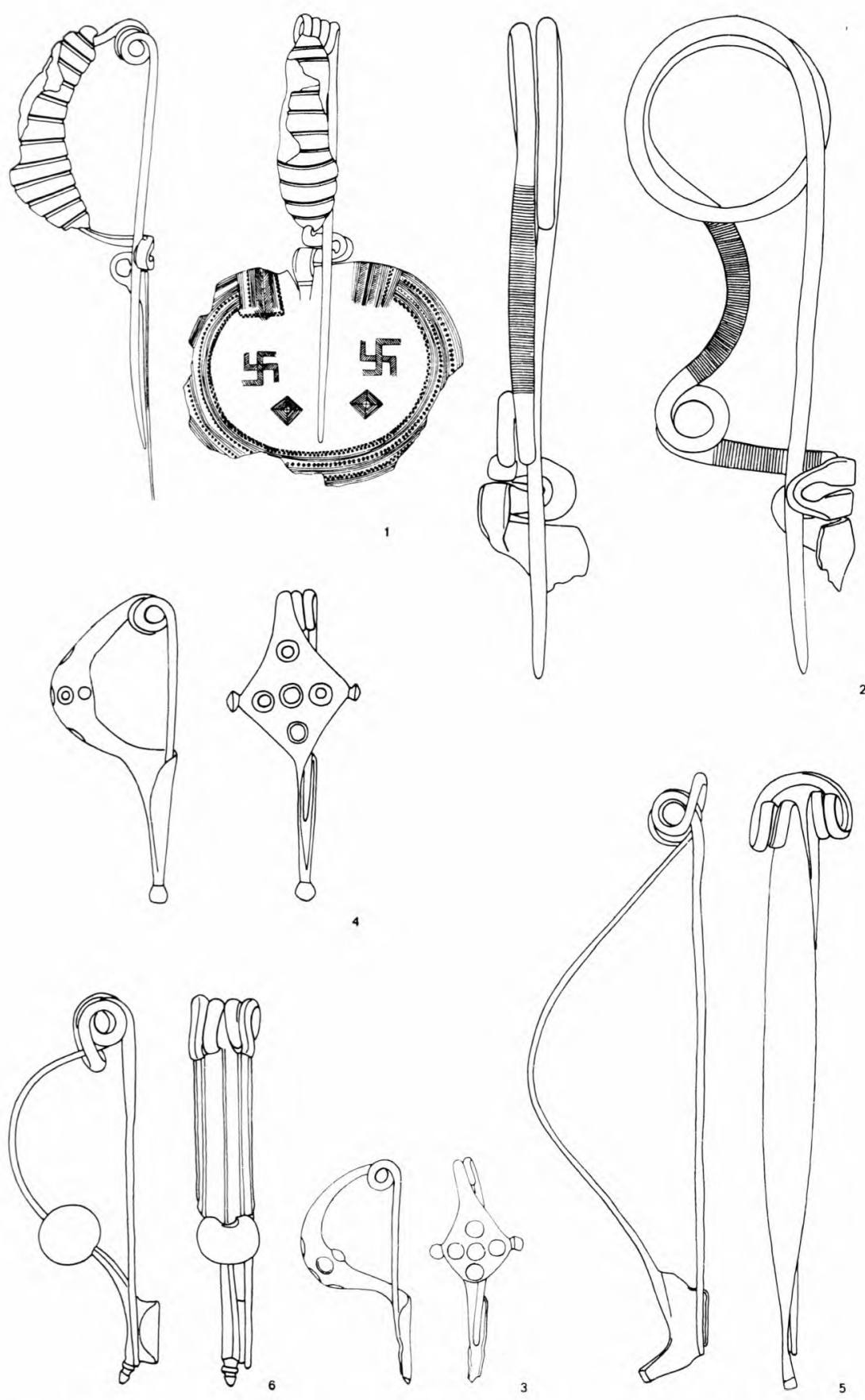

Esc. 2:3 


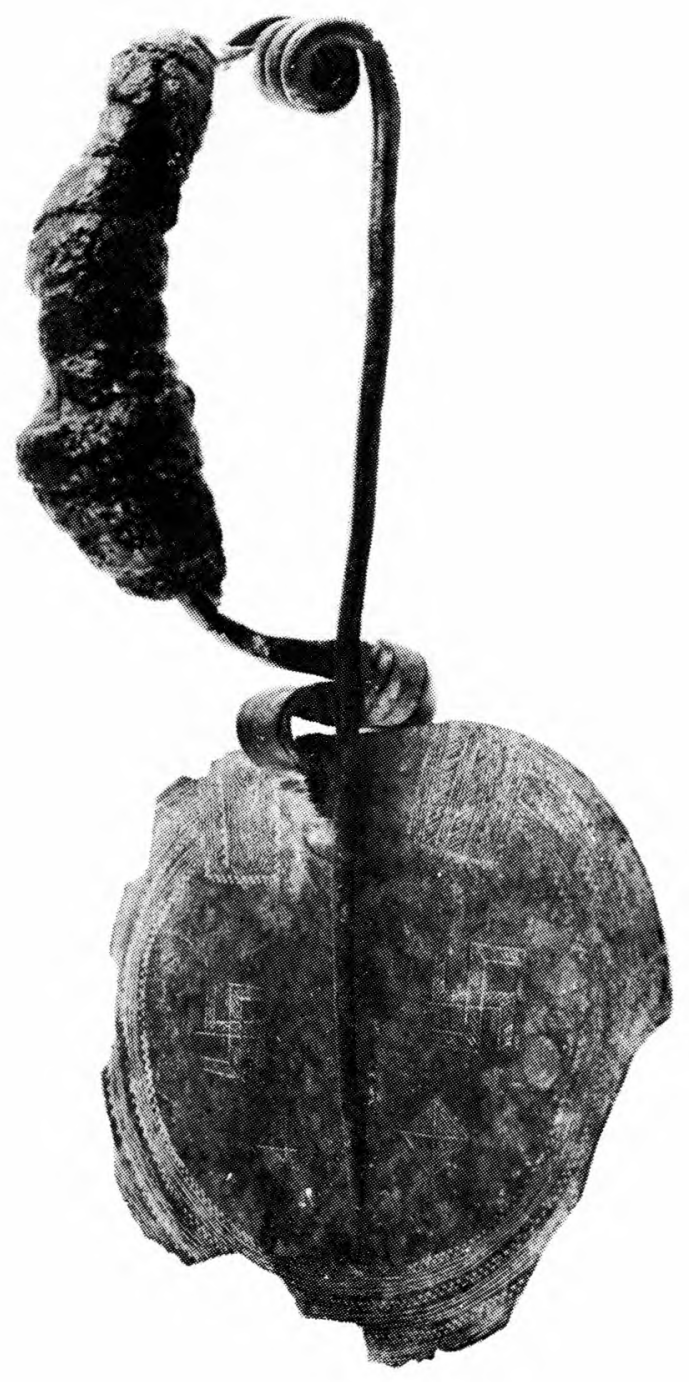

Foto 1 


$$
\Phi
$$

